\title{
'TurmaMais': uma experiência organizacional direccionada à promoção do sucesso escolar
}

\section{Resumo}

Neste artigo relata-se a experiência pedagógica 'TurmaMais' e o essencial do seu figurino organizativo. Em termos de contextualização e enquadramento teórico-conceptual sustenta-se um modelo centrado nos factores organizacionais 'dimensão' e 'estrutura composicional' da turma como referentes significativos do desempenho escolar. Os resultados observados evidenciam quebras significativas nos índices de repetência e abandono escolares e uma melhoria igualmente significativa na qualidade dos níveis escolares de coortes de alunos de $3^{\circ}$ ciclo, ten-

dendo assim a comprovar-se a eficácia do projecto. A exploração e desenvolvimento de critérios e procedimentos para a mensuração dos resultados permite, por outro lado, lançar e aprofundar o debate sobre a adequabilidade e validação de instrumentos metodológicos de análise do desempenho escolar.

Palavras-chave: Turmamais. Dimensão da turma. Estrutura composicional da turma. Sucesso escolar.

\section{Abstract \\ An organizational project directed to promote school success}

This article refers to the pedagogical experience called "Turmamais" and the essence of its organization. In terms of contextualization and theoretical and conceptual framework, it is based on a model which is centered in organizational factors such as class 'dimension' and 'compositional structure' as significative

references of school achievement. The observed results prove significative falls in school repetition and dropout and an equally significative improvement in the quality of school levels among school cohorts of 3rd. cycle students, which, thus, tends to prove the project's efficacy. The criteria and procedure exploration and development for the measurement of results allow, on the other hand, to propose and deepen 
the debate over the adequacy and validation of the methodological instruments for the analysis of school development.

Keywords: Turmamais. Class size. Class organizational structure. Educational effectiveness.

\section{Resumen}

\section{Una experiencia} organizacional dirigida a la promoción del suceso

\section{escolar}

Este artículo se refiere a la experiencia pedagógica «TurmaMais» y a laesencia de su organización. En términos de contextualización y encuadramiento teórico-conceptual sustentase un modelo centrado en los factores organizacionales «dimensión»y «estructura composicional» de la turma como referentes significativos del desempeño escolar. Los resultados evidencian reducciones significativas en los índices de repetición y abandono escolares y una mejoría igualmente significativa en la cualidad de los niveles escolares de cohortes de alumnos de tercer ciclo, comprobándose la eficacia del proyecto. La exploración y desenvolvimiento de criterios y procedimientos para la mensuración de los resultados permiten, por otro lado, lanzar y profundar el debate sobre la adecuación y validación de instrumentos metodológicos de análisis del desempeño escolar.

Palabras clave: Turmamais. Dimensión de la clase. Estructura composicional de la clase. Suceso escolar.

\section{O projecto 'TurmaMais': princípios, objectivos e aspectos organizativos}

projecto 'TurmaMais' foi iniciado, no ano lectivo 2002/03, na Escola Secundária (Sec/3 Ciclo) 'Rainha Santa Isabel', de Estre$\mathrm{moz}^{1}$ - ESRSIE, com o apoio da Direcção Regional de Educação do Alentejo - DREALE, e da Universidade de Évora, tendo como objectivo essencial melhorar significativamente a sobrevivência e sucesso escolares dos alunos do $7^{\circ}$ ano de escolaridade. Actualmente, com o apoio da Fundação Calouste Gulbenkian, a experiência foi alargada a mais três escolas do Alentejo (Redondo, Nisa e Santa Maria de Beja).

A persistência de sinais de que o nível médio das aprendizagens escolares está ainda aquém das expectadas e de que a escola continua a não conseguir produzir resultados satisfatórios numa larga percentagem de crianças e jovens provenientes de culturas não letradas é reveladora da situação frágil e deficitária em que permanece ainda o segmento da educação básica. Da aplicação de modelos analíticos da dinâmica situacional e evolutiva das populações escolares (NERDASCA, 2002), nos seus aspectos estruturais macro e microdemográficos, evidenciase uma estrutura populacional com perfis e padrões diferenciais de aproveitamento escolar cronologicamente repetitivos e tendencialmente desacelerativos e em que as disparidades de subaproveitamento e marginalização escolares inter e intra-escolas tendem a persistir ou mesmo a acentuar-se, num claro sinal de que o objectivo de uma 'escolaridade básica universal e sucedi$\mathrm{da}^{\prime}$, não só permanece longe de ser alcançada na sua plenitude, como se afigura algo incerta e problemática no quadro matricial do actual figurino organizacional escolar.

\footnotetext{
' Estremoz é uma pequena cidade situada a sul de Portugal, na região central do Alentejo.
} 
Constituem elementos expressivos e comprovativos da marca da estruturalidade do insucesso e da inadequabilidade das respostas organizacionais pedagógicas na alteração dos acontecimentos, por um lado, o padrão diferencial cronologicamente repetitivo segundo o género e a paridade que caracteriza o perfil de desempenho escolar no $3^{\circ}$ ciclo do ensino básico na sub-região do Alentejo Central, apurado com base nas variações relativas percentuais de aproveitamento (gráfico 1) e, por outro lado, o perfil de aceleração do subaproveitamento à medida que aumenta a idade e o consequente efeito pedagógico nulo da repetência que the está associado (gráfico 2).

\section{Gráfico 1 - Perfil de aproveitamento escolar por paridade e por gênero.}

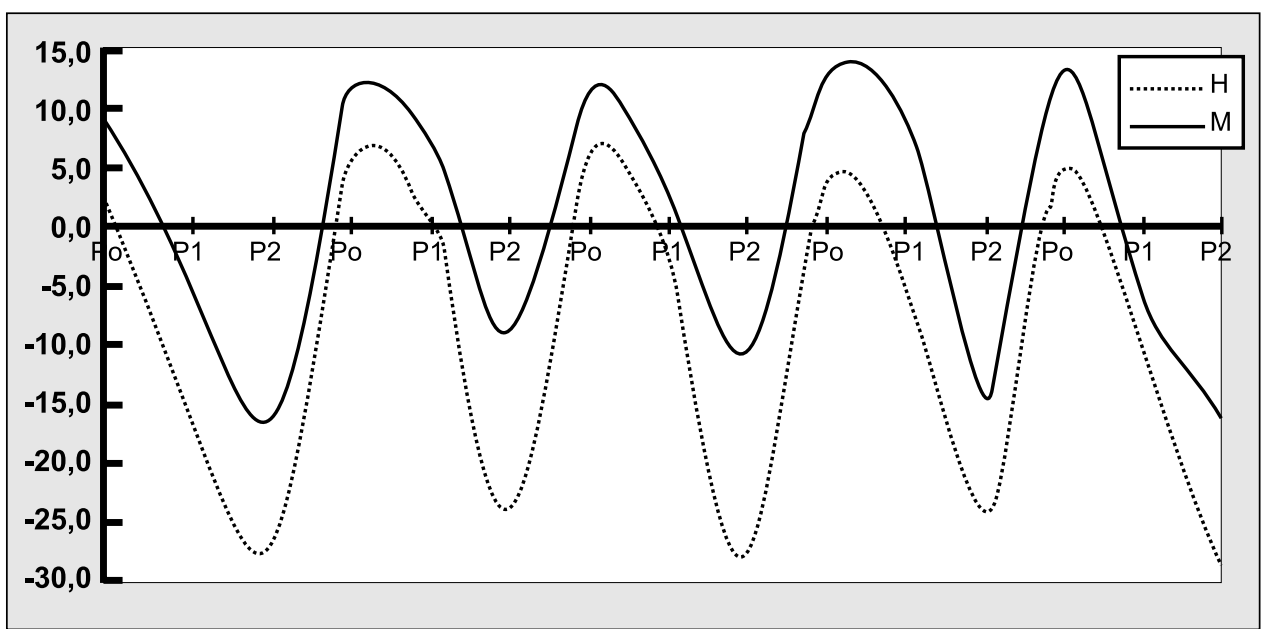

Fonte: Verdasca (2002, p. 491).

Gráfico 2: Perfil de aceleração do não-aproveitamento escolar por idade e por gênero.

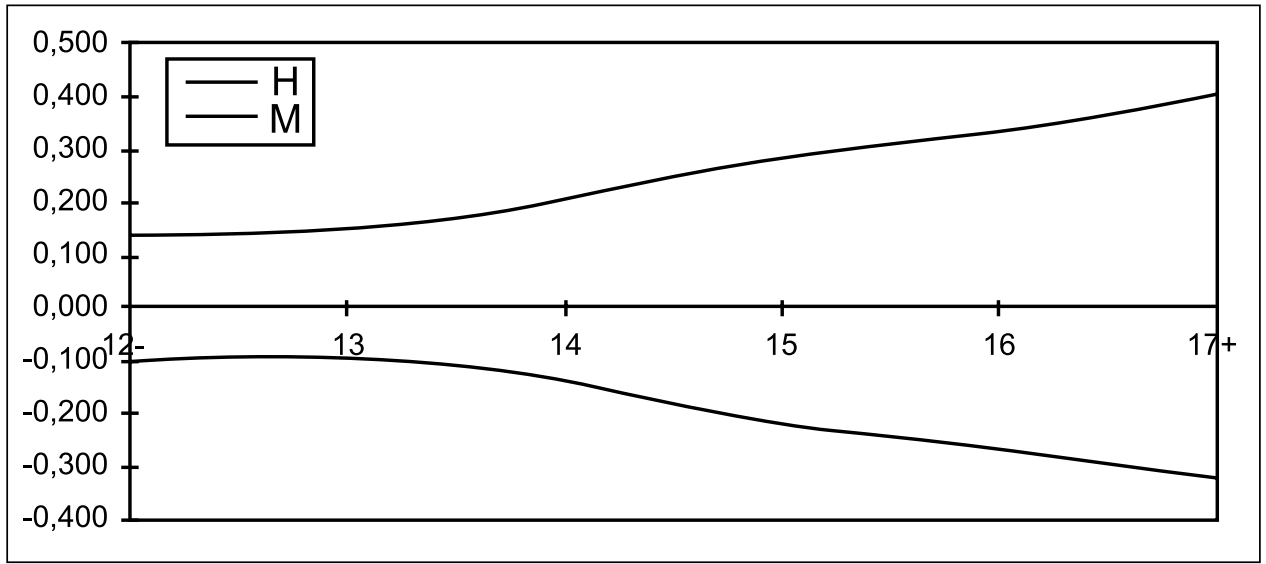

Fonte: Verdasca (2002, p. 495). 
Atendendo à elevada correlação de sentido negativo existente entre o índice de paridade e a qualidade dos resultados, afigura-se de alguma sustentabilidade a inferência de que as situações de repetência experienciadas pelos alunos ao longo dos seus itinerários escolares não parecem de modo algum ter contribuído ou estar a contribuir para uma melhoria efectiva das prestações escolares desses alunos.

Sabemos hoje que a 'mortalidade escolar' ocorrida na escola é, de certo modo, acelerada pela repetência e que, neste sentido, esta acaba por ter um efeito contrário ao que pedagogicamente se pretendia com a medida. Da análise dos resultados e dos respectivos perfis gráficos de cada um dos subgrupos amostrais, conclui-se que o subgrupo de repetentes não só desempenha abaixo dos não repetentes, como desempenha negativamente, deixando assim antever um cenário altamente provável de bi-repetência e corroborar mais uma vez a ideia de estruturalidade do problema. Podemos referir que a bi-repetência ocorre em termos relativos cerca de duas vezes mais do que a repetência (VERDASCA, 2002), o que em termos práticos vem tornar nulo ou quase nulo o efeito pedagógico pretendido com a sua aplicação. Continuar a admitir a este respeito a existência de possíveis efeitos positivos, só por via indirecta, ou seja, como uma espécie de medida que a escola e os professores têm ao dispor para eventuais regulações de acções comportamentais que favoreçam direccionamentos de conformidade e convergência escolares. Mesmo no caso de observações desagregadas por combinatórias de elementos dos perfis cartesianos constituídos a partir dos atributos sociográficos, atitudes e comportamentos dos alunos, os resultados evidenciam um padrão bastante semelhante ao pa- drão geral anteriormente referido, reforçandose assim, e ainda mais, a tese da ineficácia directa da medida, mas ao mesmo tempo, abrindo novas linhas de pesquisa no combate a um problema cuja gravidade se adensa na proporção directa da realização da universalidade educativa escolar, enquanto elemento essencial e incontornável da afirmação e aprofundamento da democracia social.

Se por um lado, no plano das variáveis organizacionais escolares, a invariável emergência de perfis configuracionais estruturantes tende a provocar um certo esvaziamento das teses reclamadoras dos 'efeitos de escola', por outro, a escola só pode afirmar-se e desenvolver-se com base na construção de acções e soluções organizacionais que recusem fatalismos antecipados e contrariem outras acomodações tendentes a enfraquecer a relevância do papel da escola nesse combate.

A essência e a base de enquadramento teórico do projecto 'TurmaMais' radicam na assunção de que a escola dispõe de campo de manobra na esfera organizacional. A definição e estabelecimento dos critérios de constituição dos agrupamentos internos de alunos são apenas algumas das variáveis que a escola pode manipular, constituindo a 'dimensão' e a 'estrutura composicional' dois dos elementos passíveis de combinação num figurino organizativo sustentado e gerador de dinâmicas potenciadores de melhorias significativas dos resultados escolares.

No plano organizativo, a 'TurmaMais' é uma turma ${ }^{2}$ sem alunos fixos, que agrega temporariamente elementos provenientes das várias turmas do mesmo ano de escolarida-

\footnotetext{
${ }^{2}$ Agrupamento interno de alunos ou classe, cuja constituição tem por base um conjunto de critérios (dimensão, idade e outras características sociográficas e escolares.
} 
de, que vão circulando de $\mathrm{x}$ em $\mathrm{x}$ semanas, normalmente cinco a seis vezes por ano lectivo. Nesta 'espécie de plataforma giratória' cada grupo fica sujeito a um horário de trabalho semelhante ao da sua turma-classe de origem, com a mesma carga horária e o mesmo professor por disciplina. Cada grupo específico de alunos continua a trabalhar os conteúdos programáticos que a sua turma-classe inicial está a desenvolver, podendo beneficiar de um apoio mais próximo e individualizado, dadas as características de certa forma semelhantes em termos de aprendizagens $^{3}$ do grupo de que faz parte, sem sobrecarga de horas semanais.

desiderato da melhoria dos resultados escolares é tão válido para os alunos com dificuldades, como para os alunos com boas prestações escolares. Ainda que o aumento do rendimento escolar seja uma meta clara a atingir, o desafio da plena integração e sobrevivência escolar de todos os alunos, em particular daqueles que se vêem remetidos para os 'últimos lugares' nos resultados escolares, constitui um desafio deveras relevante e decisivo. Com efeito, não há melhoria da qualidade educativa, sem sobrevivência escolar plena.

reforço e a afirmação das lideranças intermédias revelam-se um factor chave na deslocação do modelo de agrupamento 'turma-classe' para o agrupamento 'ano de escolaridade' e nos realinhamentos e reconfigurações que as 'novas' distribuições de alunos e docentes requerem. Manter continuadamente níveis de confiança e expectativa em alta, fomentar e desenvolver lógicas e práticas de cooperação entre docentes, docentes e alunos e alunos-alunos na sala de aula e fora dela, são acções que requerem crença, convicção, entrega e exigência numa lógica de circularidade virtuosa e viciosa e numa temporalidade que abrange no mínimo o ciclo de estudos e em que as simbologias da qualidade educativa e organizacional se afirmam agora não pelo anunciar de rituais inovatórios mas essencialmente pelos resultados escolares alcançados.

O coordenador de ano e a respectiva equipa docente têm a responsabilidade de criar os diferentes grupos de alunos, tomando como critério os níveis obtidos nas aprendizagens realizadas. Gera-se, assim, um espaço onde é possível apresentar propostas de trabalho diferentes e onde há mais possibilidades de desenvolver actividades durante um período de tempo suficiente para provocar alterações quantitativas e qualitativas nas aprendizagens e nos resultados.

A constituição e organização de equipas docentes por ano de escolaridade desencadeou uma metamorfose significativa na organização escolar. Os Conselhos de Turma transformaram-se em Conselhos de $\mathrm{Ano}^{4} \mathrm{e}$ fez-se destes a unidade nuclear agregadora, criando-se condições organizacionais para um melhor relacionamento e articulação em termos de grupo-equipa docente. Com a redução do número de professores envolvidos no acompanhamento de um ano de escolaridade torna-se possível fomentar uma lógica de equipa e criar maior coesão e espírito de cooperação e entreajuda entre todos os alunos do mesmo ano e o grupo de docentes. Deste modo, pode a equipa cumprir uma das suas mais importantes funções: encontrar soluções de trabalho viáveis para as diferentes dinâmicas de grupo surgidas, orientando as

\footnotetext{
${ }^{3}$ Estas características podem reportar-se a múltiplos critérios. Na experiência em causa o critério considerado foi o nível de aprendizagens dos alunos. Para um maior aprofundamento, ver Verdasca e Cruz (2006).
} 
actividades educativas de acordo com as características do grupo de alunos e monitorizando os respectivos resultados.

Em síntese, e em primeiro lugar, esta nova equação organizativa direccionada às vertentes socializadora e cultural-instrutiva, enquanto finalidades essenciais da educação escolar básica, inspira-se e alicerça-se no princípio do primado das soluções inclusivas e integracionistas em contexto escolar não diferenciador. Em segundo lugar, centra na liderança e coordenação intermédias a força motriz do impulso energético na organização permanente do processo de planeamento, acompanhamento e monitorização das equipas docentes e da constituição dos agrupamentos e reagrupamentos cíclicos internos de alunos. E é, porventura, na congregação simultânea destes dois elementos que radica a chave para a sustentabilidade e êxito do modelo: tudo se passa ao mesmo tempo, no mesmo espaço, com todos os alunos, sob a liderança e orientação de uma equipa docente que acredita e está apostada no desafio de conseguir provocar mais e melhores aprendizagens e, consequentemente, mais e melhores resultados escolares.

\section{Resultados: algumas leituras e interpretações}

Na ESRSIE, a experiência 'TurmaMais' já percorreu por uma vez a totalidade dos anos de escolaridade do $3^{\circ}$ ciclo, tendo sido aplicada ao $9^{\circ}$ ano pela primeira vez no ano lectivo anterior e acompanhado assim de forma continuada a geração escolar de alunos que em 2003/04 iniciou o $7^{\circ}$ ano de escolaridade e concluiria o $9^{\circ} \mathrm{em}$ 2005/06.

Os resultados permitem apurar taxas médias de retenção por ano de escolaridade, relativas ao conjunto de anos lectivos antes e após a aplicação da experiência 'TurmaMais'. Estas taxas percorrem uma extensão total de 11 anos lectivos $(7+4)$, no caso do $7^{\circ}$ ano, de $9(7+2)$, no $8^{\circ}$ ano e de 4 anos lectivos $(3+1)$, no caso do $9^{\circ}$ ano de escolaridade. $\bigcirc$ gráfico 3 resume os perfis de retenção e, por comparação, a variação relativa observada.

\section{Gráfico 3 - Taxas médias de retenção antes e após a experiência 'TurmaMais'.}

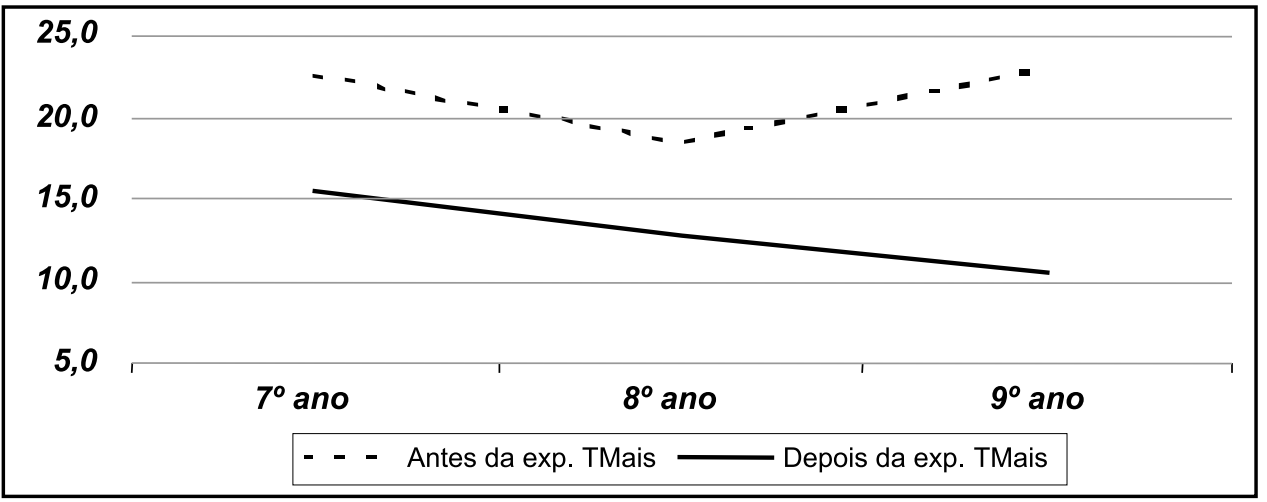

${ }^{4} \mathrm{O}$ conselho de turma (conselho de classe) é constituído por todos os professores que leccionam na turma/classe. $\bigcirc$ conselho de ano agrupa todas as turmas de um dado ano de escolaridade e integra todos os docentes que leccionam aquele ano de escolaridade. 
Da observação dos traçados gráficos constata-se a quebra significativa da retenção, qualquer que seja o ano de escolaridade, numa amplitude que oscila entre os cerca de $-31 \%$ no $7^{\circ}$ e $8^{\circ}$ anos e de $-52 \%$ no $9^{\circ}$ ano. Saliente-se, ainda, que a partir do ano lectivo 2004/05 se ampliou o nível de exigência ao reduzir-se o número de níveis inferiores a $3^{5} \mathrm{com}$ que os alunos transitam do $7^{\circ}$ para $\circ 8^{\circ}$ ano e deste para $\circ 9^{\circ}$ ano. Até esse ano os alunos puderam transitar com três níveis inferiores a 3 e a partir daquele ano lectivo restringiu-se a transição a alunos que apenas obtenham dois níveis inferiores a 3, desde que não sejam cumulativos em Língua Portuguesa e em Matemática.

Por outro lado, os efeitos da experiência parecem apontar claramente para o aumento da qualidade do sucesso escolar. Com efeito, esta é a conclusão que se pode extrair quando se observa um acréscimo de cerca de $32 \%$ nos níveis 4 e 5 contra um decréscimo de $-52 \%$ nos níveis 1 e 2, respectivamente antes e após o arranque da experiência 'TurmaMais'. gráfico 4 resume a evolução qualitativa referida.

\section{Gráfico 4 - Evolução da qualidade do sucesso escolar.}

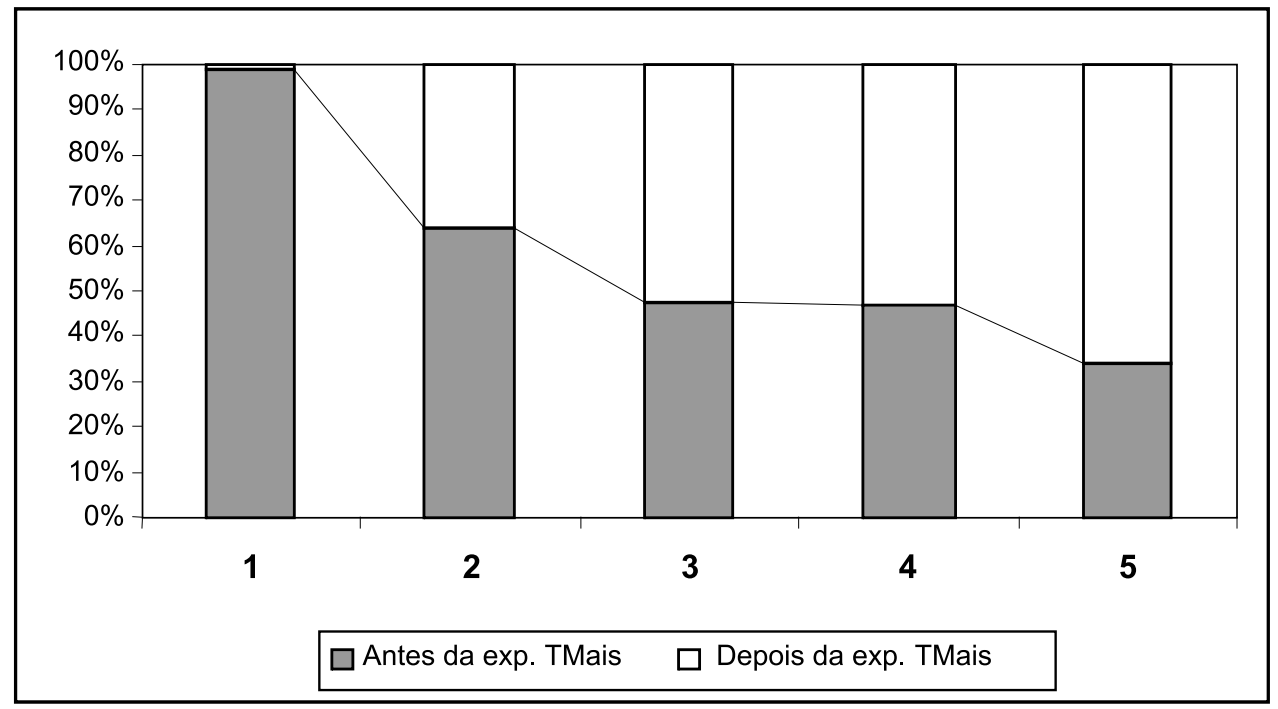

\footnotetext{
${ }^{5} \mathrm{O}$ corredor da escala de avaliação utilizada vai de 1 a 5. Os níveis 1 e 2 traduzem desempenho negativo; os níveis 3,4 e 5 traduzem desempenho positivo, correspondendo o nível 5 à menção de excelente.
} 
Da análise dos diversos resultados depreende-se que a experiência 'TurmaMais' tem funcionado como uma plataforma organizacional pedagógica que tem conduzido quer a uma melhoria substantiva dos resultados escolares dos alunos, quer a uma acção integradora onde o espírito e as práticas de cooperação e de entreajuda entre os alunos e grupos de alunos constituem uma mar- ca distintiva de uma socialização escolar coesa e solidária.

Por outro lado, o efeito positivo da experiência na sobrevivência escolar dos alunos reforça-se ainda mais quando se comparam os índices de sobrevivência e realização escolares de diversas escolas de municípios limítrofes e de contextos ecologicamente semelhantes ${ }^{6}$.

\section{Gráfico 5 - Índice de probabilidade de sucesso escolar (pse). ${ }^{7}$}

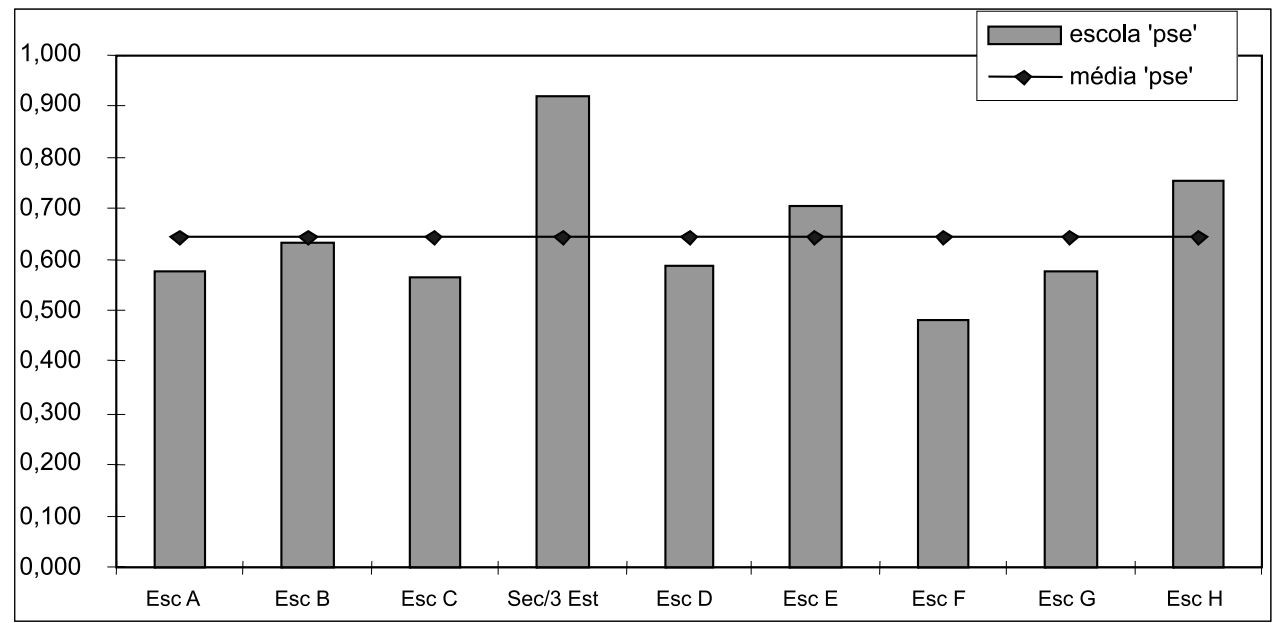

${ }^{6}$ Por questões de ordem ética, mantemos sob reserva a identificação das restantes escolas.

7 A probabilidade de sucesso escolar (pse) corresponde, no fundo, a um quociente de sobrevivência escolar (QSE) e é o complemento da probabilidade ou quociente de mortalidade escolar (abandono escolar). Distingue-se do quociente de sobrevivência, pelo facto de este ser utilizado para referenciações a anos curriculares intermédios do ciclo de estudos, enquanto que a probabilidade de sucesso se reporta ao ciclo de estudos na sua globalidade. Este indicador é um importante elemento de análise da eficácia interna escolar, já que informa da probabilidade que um qualquer aluno tem, ao iniciar um determinado ciclo de estudos, de vir a sair diplomado no final desse ciclo de estudos. $\bigcirc$ seu procedimento de cálculo baseia-se, assim, na relação entre os diplomados realizados e os novos inscritos que integram o fluxo escolar inicial, ou seja, os novos inscritos em to e expressa-se, simbolicamente, do seguinte modo: pse = å D / Nlto. Para um maior aprofundamento, ver Verdasca (1995, 2002). 
Como se depreende do gráfico anterior, apenas três das nove escolas em análise superam o valor médio 'pse' (0.644), sendo a ESRSIE a que apresenta, de longe, o melhor resultado, conseguindo mais $22 \%$ que a Esc ' $\mathrm{H}$ ', a segunda com melhor índice 'pse' e mais 91\%, quase o dobro, que a Esc ' $F$ ', a de menor índice de probabilidade de sucesso escolar de paridade zero. A capacidade revelada pela ESRSIE na diplomação, em três anos lectivos, de $92 \%$ dos alunos que iniciaram o $7^{\circ}$ ano em 2003/04, contra os apenas $61 \%$ de média que as restantes oito escolas conseguiram atingir no mesmo período, constitui outro revelador das potencialidades da experiência 'TurmaMais' na fixação dos alunos a percursos regulares de escolarização no quadro da educação escolar básica.

Por outro lado, a análise dos resultados de exame de $9^{\circ}$ nas disciplinas de Português e Matemática no final do ano lectivo 2005/06 entre as várias escolas, parece sustentar uma certa tendência para uma correlação negativa entre o índice de sobrevivência geracional e as classificações do grupo sobrevivente em exame. Esta correlação de sentido negativo é de certa forma explicável por uma espécie de efeito depurador que o próprio abandono ou retenção acaba por exercer no grupo sobrevivente. Com efeito, parece tolerável que uma escola que apresenta a exame a geração escolar completa ou quase completa que iniciou o ciclo possa vir a conseguir uma menor prestação média em exame dos seus alunos do que uma outra escola que no decorrer do ciclo depurou ou pouco fez para evitar a depuração de uma parte significativa do grupo geracional inicial.
Concretizando: se dos 100 alunos de uma geração se apresentam em exame apenas 50, porque os restantes já abandonaram, ficaram retardados no seu itinerário escolar ou mudaram de rede formativa, é bem provável e até expectável que os 50 sobreviventes possam vir a desempenhar bem melhor em exame do que os de uma outra coorte escolar que não sofreu neste percurso depuração e se apresenta na sua totalidade a prestar provas. A metáfora desportiva das provas regionais dos 100 metros serve aqui de ilustração. No caso da escola ' $X$ ', só os alunos que não ultrapassavam a barreira dos 12 segundos eram enviados para a prova, reduzindo a representação da escola apenas àqueles que tinham conseguido realizar esses tempos e não constituindo propriamente um feito de maior o facto de a escola vir a conseguir um tempo médio inferior a 12 segundos. No caso da escola ' $Y$ ', a participação na prova era alargada à totalidade dos alunos independentemente dos tempos realizados; apesar de vários terem conseguido tempos inferiores a 12 segundos, a maioria fez tempos superiores e a escola saiu prejudicada na sua média final. $\bigcirc$ que se deve privilegiar, a primeira ou a segunda das opções? Não haverá provavelmente uma só resposta, pelo facto de a mesma não ser independente de factores de contexto e da respectiva finalidade e função social esperada. Naturalmente que num contexto de escolaridade básica de cariz universal e em idade de frequência escolar obrigatória a segunda opção fará provavelmente mais sentido e cumprirá de forma bem mais coerente com princípios de coesão educativa, socialização e igualdade de oportunidades. 
Na verdade, a principal dificuldade parece estar no encontrar de um ponto de equilíbrio razoável entre os dois índices, dado que perante a tendencial correlação negativa entre a sobrevivência escolar e as classificações finais de exame, importará necessariamente estabelecer os limites de uma margem de tolerância aceitável.

\section{Gráfico 6 - Traçados comparativos 'pse' e 'classificações de exame' (valores normalizados) ${ }^{8}$.}

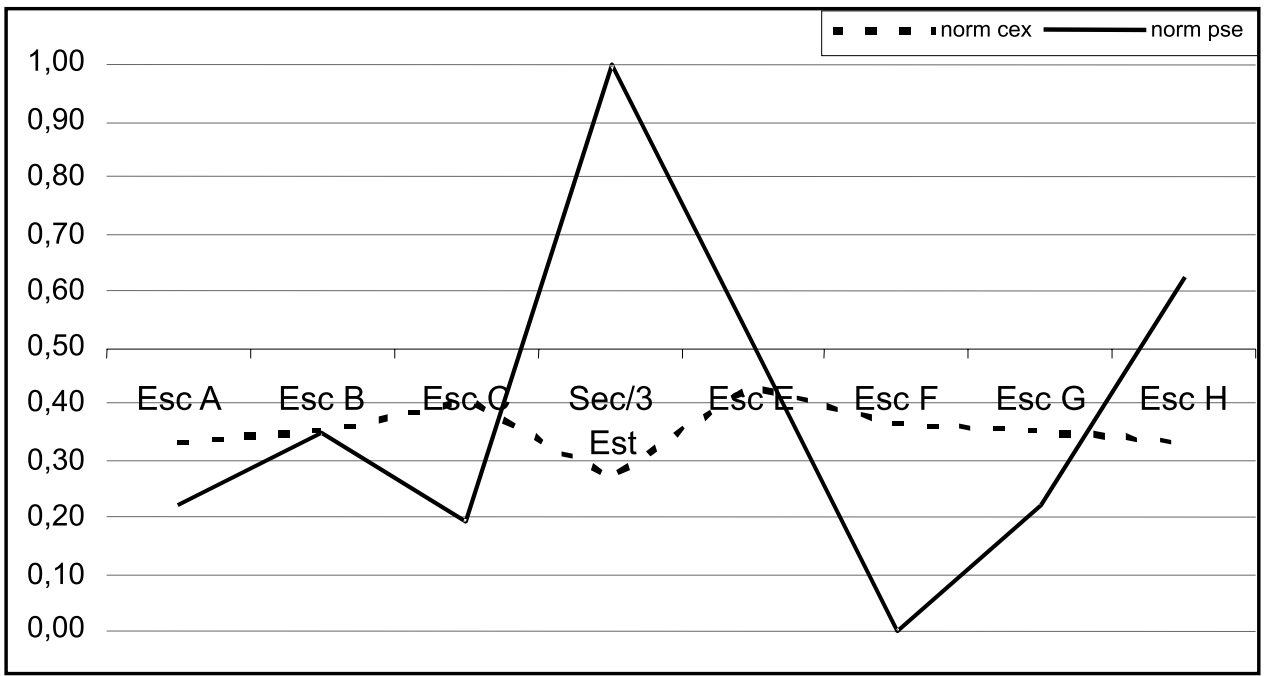

A regressão quadrática é, de entre muitas outras, uma das opções metodológicas possíveis para a fixação dessas margens. Assim, tomando por referência os respectivos índices 'pse' e 'classificações de exame de Matemática' ('cex') em 2005/06 das escolas em análise, obtém-se a equação de modelização correspondente $(Y=$ $\left.0.746+5.625 X-4,523 X^{2} ; R^{2}=0.493\right)$, a partir da qual, e para um determinado grau de confiança, é possível projectar valores de classificação de referência abaixo dos quais as prestações escolares de uma determinada escola tenderiam a ser consideradas problemáticas.
Outra opção possível, e relativamente bem mais simples, é a que podemos designar de 'diferencial algébrico', calculado a partir da soma algébrica da diferença entre cada índice 'pse' normalizado e a respectiva média com a diferença entre cada 'classificação de exame' normalizada e a respectiva média. Um diferencial positivo traduz posições relativas superiores à média de ambas as variáveis (superavit) ou um 'superavit pse' superior ao 'défice classificação de exame'; um resultado negativo traduz o contrário, ou seja, posições relativas inferiores à média de ambas as variáveis ou um 'défice pse' superior ao 'superavit cex'.

\footnotetext{
${ }^{8}$ Dado que os valores das variáveis estão expressos em unidades diferentes, para que se possam estabelecer comparações normalizou-se a informação reduzindo-a a valores compreendidos entre 0 (para o pior valor) e 1 (para o melhor valor).
} 


\section{Gráfico 7 - Diferencial algébrico reportado a valores normalizados 'pse' e 'cex'.}

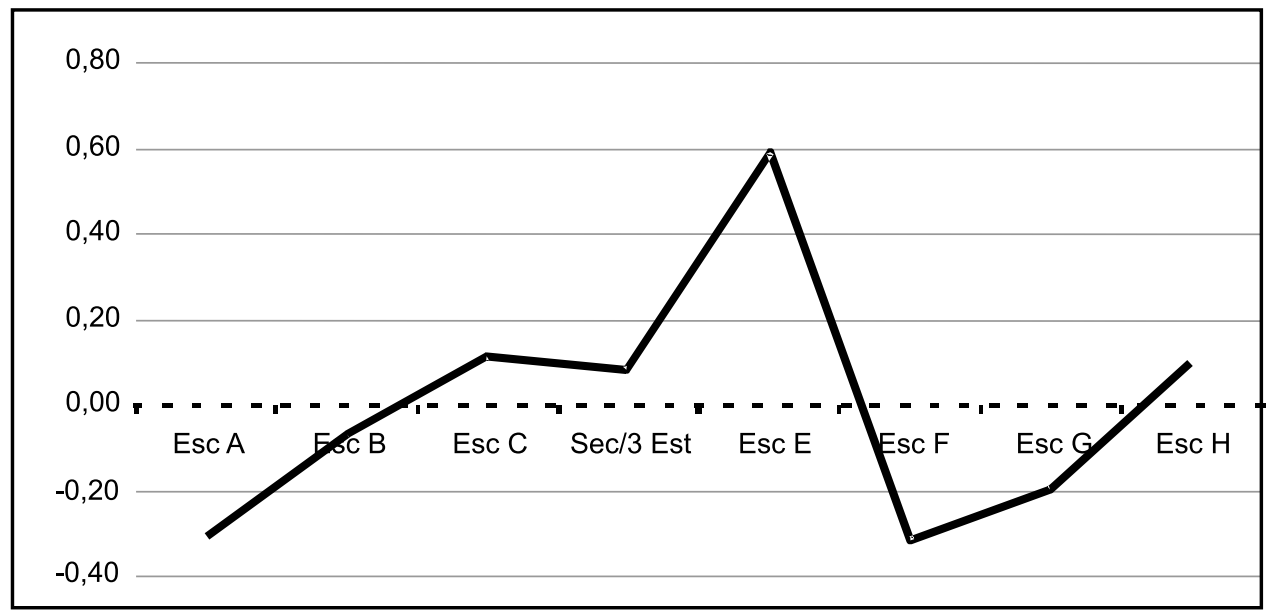

Em registo gráfico, a primeira situação está traduzida nos casos das escolas ' $\mathrm{C}$ ', 'Sec/3 Est', 'E' e 'H'; a segunda situação através das escolas 'A', 'B', ' $F$ ' e ' $G$ '.

Outra solução a explorar é a que assenta na combinatória 'pse'/'resultados de exame' pelo critério 'média aritmética simples' ou 'média ponderada'. O recurso a valores normalizados permite, aliás, expressar o resultado final de desempenho no intervalo de valores $[0 ; 1]$. A opção pelo primeiro critério traduz uma situação de igual ponderação para ambas as variáveis; a opção pela média ponderada permite acentuar a relevância de uma delas em detrimento da outra, podendo essa ponderação flutuar em função dos níveis de ensino, do segmento formativo ou de qualquer outro aspecto que se pretenda fazer relevar. Assim, por exemplo, se se considerar que ao nível da educação escolar básica o objectivo da universalização da frequência escolar é bem mais significativo do que a prestação dos alunos em exame, então o peso da variável 'pse' para o apuramento final do resultado poderia ser superior à ponderação a atribuir à variável 'resultados de exame'.

$\mathrm{Na}$ solução construída e resumida graficamente, apesar de tomar por referência dados respeitantes ao $3^{\circ}$ ciclo do ensino básico, privilegiou-se o equilíbrio optando-se pela utilização da média aritmética simples. 


\section{Gráfico 8 - O desempenho escolar centrado na combinatória sobrevivência e resultados em exame.}

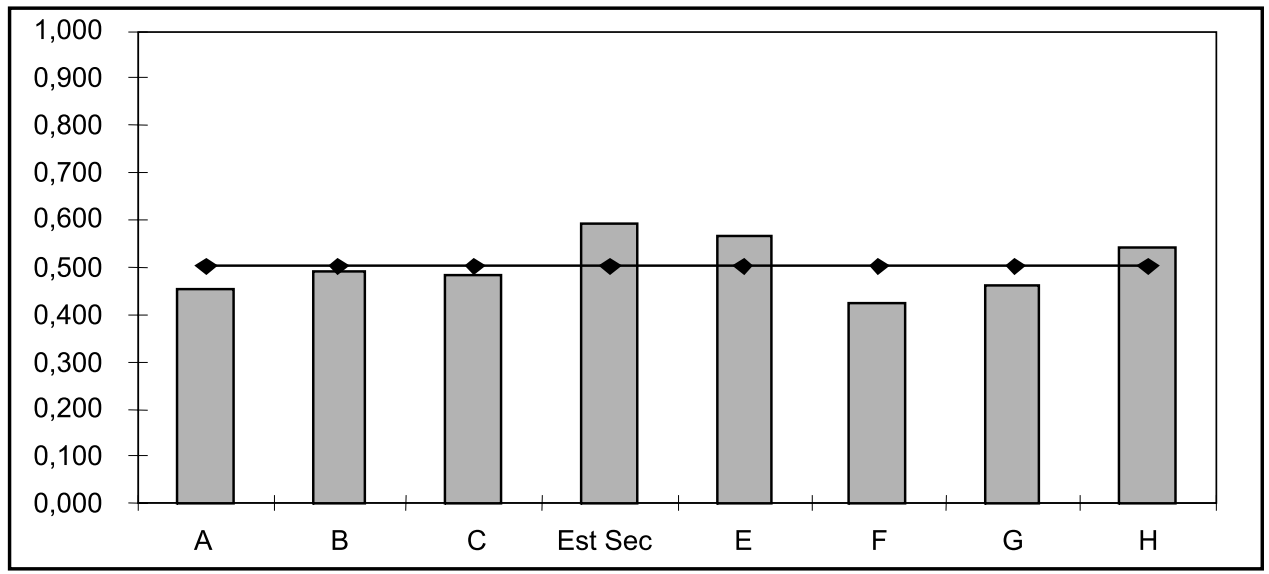

A melhor pontuação em termos de desempenho pertence à escola ESRSIE; por outro lado, de quatro, passam apenas para três, as escolas com desempenho acima da média do grupo: 'Sec/3 Est', ' $E$ ' e ' $\mathrm{H}^{\prime}$. Tratando-se de um contexto de $3^{\circ}$ ciclo do básico", o desiderato de uma escolarização universalmente sucedida suporta-se em acções estratégicas de igualização de oportunidades, de inclusão e coesão educativas, de solidariedade, cooperação e apoio na acção, ou seja, em medidas e acções concretas que fazem da sobrevivência e integração plenas as suas preocupações e desafios escolares maiores.

Os resultados finais projectados devem merecer por isso uma leitura crítica e atenta, deles se depreendendo, perante um tal critério, a posição final de destaque das escolas 'Sec/3 Est', ' $\mathrm{E}$ ' e ' $\mathrm{H}$ ' face às restantes.

\section{Notas finais}

O lançamento da experiência 'TurmaMais' e todo o trabalho de sensibilização, motivação e envolvimento de professores e outros actores educativos que lhe está subjacente, levou ao mergulhar no seio da escola e à emergência de espaços e tempos de problematização, pensamento e análise crítica sobre o trabalho escolar realizado, natureza, opções tomadas e modos de concretização. Estes momentos de exercício crítico, consubstanciados na realização de diagnósticos 'clínicos' organizacionais, análises das situações escolares e equacionamento de soluções contextualizadas, mas também no redesenho e reorganização de estruturas e grupos, produziram novas lógicas de orientação e novas apropriações organizacionais, direccionamentos e modos de agir na escola, fazendo da melhoria dos resultados escolares, traduzidos no desafio de con-

\footnotetext{
${ }^{9}$ Em Portugal, a escolaridade obrigatória vai do $1^{\circ}$ ao $9^{\circ}$ ano de escolaridade, distribuídos por três ciclos de escolaridade: do $1^{\circ}$ ao $4^{\circ}$ ano, $1^{\circ}$ ciclo; do $5^{\circ}$ ao $6^{\circ}$ ano, $2^{\circ}$ ciclo; do $7^{\circ}$ ao $9^{\circ}$ ano, $3^{\circ}$ ciclo. Em termos de idade abrange as crianças dos seis aos quinze anos.
} 
seguir o pleno em termos de inclusão escolar e no crescimento da qualidade dos resultados, o seu objectivo nuclear.

Na base deste desafio reconhecemos cinco princípios orientadores e que passamos a enunciar: 1) princípio da universalização da igualização de oportunidades de acesso e êxito escolares, uma bandeira de toda e qualquer escola que pretenda promover a justiça educativa, aprofundar a democracia e afirmar a cidadania; 2) princípio da orientação aos resultados, fazendo das múltiplas iniciativas e projectos escolares instrumentos e meios estratégicos cuja relevância se afirma e reconhece ou se esvai e desaparece na justa medida em que potenciem ou não mais e melhores aprendizagens traduzidas em mais e melhores resultados; 3) princípio da solidariedade e cooperação, garantido através de apoio educativo e acompanhamento tutorial aos alunos, com recurso a acções de apoio individualizado e a trabalho cooperativo, fomentando a responsabilidade partilhada e o espírito de grupo e envolvendo no seu planeamento e concretização equipas docentes; 4) princípio da autoregulação e progresso, como forma de manter uma vigilância e pressão permanentes sobre o andamento dos acontecimentos e potenciar a melhoria constante de resultados, organizando, distribuindo e monitorizando as actividades de apoio e acompanhamento; 5) princípio do ideário de serviço público, cuja afirmação e aprofundamento dependerá da qualidade do serviço público de educação prestado à comunidade, designadamente, em termos da igualização de oportunidades, das realizações escolares alcançadas, do apoio sócio-educativo e tutorial efectivado, dos incrementos de melhoria e progresso conseguidos nos seus resultados.

Em jeito de conclusão, e talvez mesmo de recomendação, cabe agora à ESRSIE e às equipas docentes envolvidas no projecto, em colaboração com outras estruturas de orientação e aconselhamento escolar, dar continuidade ao trabalho construído, por forma a que os cerca de nove (e tal) alunos em cada dez que concluíram $\circ 3^{\circ}$ ciclo em três anos, continuem os seus percursos educativos e formativos nas redes e modalidades de qualificação que os seus interesses, capacidades e expectativas aconselhem.

E esse terá que ser necessariamente o passo seguinte; de outro modo, restará a estranha sensação que depois de um longo e aturado trabalho em prol da melhoria da qualidade educativa, mas também e consequentemente do aprofundamento da democracia educativa e social, alguma coisa ficou por realizar e aquém de um objectivo igualmente essencial e porventura de um desafio ainda de maior alcance. 


\section{Referências}

ESRSIE; DREALE. Relatório de acompanhamento e avaliação do projecto 'TurmaMais'. Estremoz, 2004. Policopiado.

- Relatórios de acompanhamento e avaliação do projecto 'TurmaMais'. Estremoz, 2005. Policopiado.

. Relatórios de acompanhamento e avaliação do projecto 'TurmaMais'.

Estremoz, 2006. Policopiado.

VERDASCA, J. L. C. Desempenho escolar, dinâmicas de evolução e elementos configuracionais estruturantes: os casos do $2^{\circ}$ e $3^{\circ}$ ciclos do básico nos municípios de Évora e de Portel. 2002. Tese (Doutorado)-Universidade de Évora, Évora, 2002.

VERDASCA, J. L. C.; CRUZ, T. O projecto 'TurmaMais': dialogando em torno de uma experiência de combate ao insucesso e abandono escolares. Revista Portuguesa de Investigação Educacional: revista da Universidade Católica Portuguesa, Lisboa, n. 4, 2006. No prelo.

Recebido em: 11/04/2007

Aceito para publicação em: 13/05/2007 